\title{
Retraction Note to: Relationship between inflammatory cytokines and risk of depression, and effect of depression on the prognosis of high grade glioma patients
}

\author{
Jian-tong Jiao ${ }^{1} \cdot \mathrm{Jun} \mathrm{Sun}^{1} \cdot$ Jian-fen $\mathrm{Ma}^{1} \cdot$ Min-chao Dai ${ }^{1} \cdot \mathrm{Jin}$ Huang ${ }^{1}$ Chen Jiang ${ }^{1}$. \\ Cheng Wang ${ }^{1} \cdot$ Chao Cheng ${ }^{1} \cdot$ Jun-fei Shao ${ }^{1}$
}

Published online: 18 August 2017

(C) Springer Science+Business Media, LLC 2017

Retraction Note to: J Neurooncol (2015) 124:475-484

DOI 10.1007/s11060-015-1861-7

The Editor and Publisher have retracted this article because the authors are unable to provide sufficient documentation of the study, including details of all the patients treated that would substantiate the facts in this paper. The authors disagree with this retraction.

The online version of the original article can be found under doi: 10.1007/s11060-015-1861-7.

Jun-fei Shao

wxhneurosurgery@126.com

Jian-tong Jiao

tongjianjiao@126.com

1 Department of Neurosurgery, Wuxi People's Hospital of Nanjing Medical University, Wuxi 214023, China 